DOI:10.2151/jmsj.87.849

\title{
Atmospheric Turbidity Estimation from Hourly Global Solar Radiation Data under Cloudless Skies
}

\author{
Yoshimitsu MASAKI, Tsuneo KUWAGATA and Yasushi ISHIGOOKA \\ National Institute for Agro-Environmental Sciences, Tsukuba, Japan
}

(Manuscript received 24 December 2008, in final form 6 June 2009)

\begin{abstract}
We estimated monthly atmospheric turbidity from hourly observation data of global solar radiation under cloudless skies at 67 stations all over Japan. Using an empirical formula for calculating global solar radiation, we determined atmospheric turbidity as the best-fit parameter. The estimated turbidity is consistent with the observation by the Japan Meteorological Agency. Sub-nationwide increases in atmospheric turbidity, caused by forest fires or Asian dust events, are detected in time series. Some temporal changes in atmospheric turbidity are also found in a small area. Such local phenomena are hardly detectable by sparse distribution of the stations for direct solar radiation observation. The accuracy of the global solar radiation estimation can be improved by considering the seasonal variation of the turbidity. Since Ångström's turbidity coefficient is directly linked with the volumetric aerosol content, the present method is useful for monitoring the spatial distribution of aerosols. In addition, the present method using the densely distributed observation network of global solar radiation has an advantage in compensating for the sparseness of the current atmospheric turbidity observation in Japan.
\end{abstract}

\section{Introduction}

Global solar radiation (GSR) is the net solar incident shortwave energy received at the ground. A large part of GSR energy is directly received from the Sun, but a certain part is also received from the sky as diffuse irradiance. The accurate estimation of solar radiation is important not only for studies on meteorology and climate but also for studies in many application fields. Agricultural application is one of such examples: The photosynthetic activity of plants directly controls their growth, and the soil and plant root temperatures are also affected by solar radiation.

Atmospheric molecules and small particles floating in the air interact with the incident radiation and weaken the radiant energy. The extinction ratio

Corresponding author: Yoshimitsu Masaki, National Institute for Agro-Environmental Sciences, 3-1-3, Kannondai, Tsukuba, Ibaraki, 305-8604, Japan.

E-mail: ymasaki@affrc.go.jp

(C) 2009, Meteorological Society of Japan of the radiation largely depends on meteorological conditions along the path of the incident radiation. The experimental formulae proposed by Kondo and Miura (1983) (hereafter, KM-83) are one example for calculating GSR under various meteorological conditions. They used the precipitable water, atmospheric turbidity, and surface albedo in their formulation.

However, errors in the turbidity parameter may produce significant errors in the GSR calculation. Roughly speaking, with typical parameters for Japan, errors of 0.01 in Ångström's turbidity coefficient deviate $1 \%$ of the GSR, while errors of 0.01 in surface albedo deviate $0.14 \%$ of the GSR, according to the KM- 83 . Since the surface albedo lies between 0.1 to 0.3 at most land areas (except for snow-covered areas), as we see in Lamb (1972), expected errors in GSR are 3\% of the GSR at maximum. On the other hand, turbidity differences between urban and rural areas are sometimes $\sim 0.1$. Seasonal variation of the turbidity in cities in Japan is also $\sim 0.1$. Judging from these conditions, expected errors may reach $5 \%$ or more of the GSR. 
Time and geographical variations of turbidity have been studied by many researchers. Roosen et al. (1973) summarized 50 years' results of atmospheric transmissivity observation at 13 observatories worldwide and depicted clear seasonal variations. Regional distribution of turbidity in the United States was reported by Flowers et al. (1969).

In Japan, Yamamoto et al. (1968) proposed a derivation of the Ångström's turbidity coefficient from unfiltered direct solar radiation (DSR) data and showed seasonal distribution of turbidity all over Japan and neighboring areas. Kondo (1967) estimated attenuation of GSR due to atmospheric turbidity in 12 cities in Japan. Murai and Yamauchi (1975) estimated the effective atmospheric transmissivity from GSR observation data at 65 stations in Japan. Yoshida and Shinoki (1978) depicted the GSR distribution charts for Japan with improved data sets and they discussed turbidity variation caused by air pollution. After eruptions of a volcano, sudden increases in turbidity have been reported (Yamauchi 1995).

Atmospheric turbidity in Japan has been monitored through DSR observation by the Japan Meteorological Agency (JMA). The JMA operates routine DSR observation at 14 stations until September 2007 (unfortunately, at four stations after October 2007 (Japan Meteorological Agency, 2007)). On the other hand, the turbidity largely varies with geographical locations, seasons or ob- servation dates (e.g., Yamamoto et al. 1968; Flowers et al. 1969) and results in large variations of GSR. The current DSR observation network is not sufficiently dense for depicting geographical variations of the turbidity.

In this paper, we estimate the geographical distribution of monthly turbidity variation to improve the estimation of GSR data. We utilize hourly GSR observation at 67 surface observation sites of the JMA. In this study, nationwide analysis on monthly variations of atmospheric turbidity with a high geographical resolution is remarkable. We have attempted to improve the accuracy of atmospheric turbidity estimation by setting stringent criteria for the analysis. First, we explain a method for determining the turbidity parameter from the GSR observation data in Section 3. Based on the KM-83 theory (Section 3.1), a key strategy for finding the best-fit atmospheric turbidity (Sections 3.2-3.3) is described. Next, we show the atmospheric turbidity results in Sections 4 and 5 and discuss its application to the GSR estimation in Section 6.

\section{Data sets}

We use hourly meteorological data (GSR, sunshine duration, surface air pressure, temperature, water vapor pressure) at the 67 stations listed in Table 1. Two analysis periods are set for different purposes: (1) for validity check of our estimated turbidity at 14 DSR stations: 16 years' data from

Table 1. Meteorological observation stations used in this study. ID gives the last three digits of the station number

(47xxx). Numbers in brackets show the scheduled number of cloud amount observation per day (ClObs). The symbol $\dagger$ denotes stations where direct solar radiation is observed until September 2007 (14 stations).

\begin{tabular}{|c|c|c|c|c|c|c|c|}
\hline ID & Station & ID & Station & ID & Station & ID & Station \\
\hline 401 & Wakkanai (7) & 587 & Sakata (7) & 655 & Omaezaki (7) & 815 & Oita (7) \\
\hline 402 & Kitamiesashi (2) & 588 & Yamagata (4) & 656 & Shizuoka (3) & 817 & Nagasaki (7) \\
\hline 406 & Rumoi (7) & 590 & Sendai (7) & 662 & Tokyo (7) & 819 & Kumamoto (7) \\
\hline 407 & Asahikawa (7) & 595 & Fukushima (4) & 675 & Oshima (7) & 827 & Kagoshima $(7) \dagger$ \\
\hline 409 & Abashiri (7) & 598 & Onahama (7) & 678 & Hachijojima (7) & 830 & Miyazaki (7) \\
\hline 412 & Sapporo $(7) \dagger$ & 600 & Wajima $(7) \dagger$ & 744 & Yonago $(3) \dagger$ & 887 & Matsuyama (7) \\
\hline 417 & Obihiro (4) & 604 & Niigata (7) & 750 & Maizuru (7) & 891 & Takamatsu (7) \\
\hline 420 & Nemuro $(7) \dagger$ & 607 & Toyama (4) & 755 & Hamada (7) & 893 & Kochi (4) \\
\hline 421 & Suttsu (7) & 612 & Takada (7) & 761 & Hikone (3) & 898 & Shimizu $(7) \dagger$ \\
\hline 423 & Muroran (4) & 615 & Utsunomiya (4) & 762 & Shimonoseki (7) & 909 & Naze (7) \\
\hline 426 & Urakawa (7) & 616 & Fukui (3) & 765 & Hiroshima (7) & 918 & Ishigakijima $(7) \dagger$ \\
\hline 430 & Hakodate (7) & 618 & Matsumoto $(7) \dagger$ & 772 & Osaka (7) & 927 & Miyakojima (7) \\
\hline 575 & Aomori (7) & 624 & Maebashi (7) & 778 & Shionomisaki $(7) \dagger$ & 936 & Naha $(7) \dagger$ \\
\hline 581 & Hachinohe (7) & 636 & Nagoya (7) & 780 & Nara (3) & 945 & Minamidaitojima (7) \\
\hline 582 & Akita $(7) \dagger$ & 638 & Kofu (7) & 800 & Izuhara (7) & 971 & Chichijima (7) \\
\hline 584 & Morioka (7) & 646 & Tateno $(2) \dagger$ & 807 & Fukuoka $(7) \dagger$ & 991 & Minamitorishima (4) \\
\hline 585 & Miyako (7) $\dagger$ & 648 & Choshi (7) & 813 & Saga (3) & & \\
\hline
\end{tabular}


1991 to 2006 , (2) for estimating monthly turbidity at 67 GSR stations: eight years' data from 1999 to 2006.

Meteorological instruments installed at JMA's stations have been renovated at a decadal interval. The old meteorological instruments, the JMA- 80 type, have been replaced by the latest ones, the JMA-95 type, since the 1995 fiscal year. We distinguish between two types of instruments to check their characteristics.

The Sun's position on the celestial sphere is commonly calculated with a simple formula, in which only the annual variation of the Sun's declination is considered. However, in order to obtain hourly GSR, we should pay attention to the annual variation of the Sun's longitudinal position, known as 'the equation of time'. Since the right ascension of the 'real Sun' moves ahead of/behind the 'mean fictitious Sun' by about 15 minutes at most, this anomaly cannot be negligible in the evaluation of hourly GSR.

In this study, we use the simple form of celestial ephemeris proposed by Nagasawa (1999). This ephemeris is constructed with a truncated trigonometric series of positions of the celestial bodies and is sufficiently accurate for the hourly GSR calculation. We adopt $\Delta T$ (the parameter between two time systems of the ephemeris time and the universal time $)=60$ seconds for our calculation.

To calculate hourly GSR, we evaluate instantaneous GSR with instantaneous meteorological data, which is estimated from hourly meteorological data by linear interpolation at every second. If the time interval of two adjoining data is more than one hour, we do not use the data nor do we estimate the hourly GSR. Then we integrate instantaneous GSR for over 3600 seconds.

\section{Method}

\subsection{GSR calculation scheme}

Estimation of GSR commonly requires two calculation steps. (1) The first step is calculations of the Sun's distance from the Earth and its position on the celestial sphere. They give the solar input energy on a local horizontal plane at the top of the atmospheric layer. In this calculation, time and geographical conditions are necessary as the inputs. (2) The second is the estimation of the reduction of the solar incident energy while it travels through the atmosphere. Formulae for the purpose have been developed on a theoretical basis and their parameters are determined experimentally.
In order to estimate hourly GSR, we use the KM-83 formulae. The KM-83 is fundamentally based on a theoretical background of atmospheric optical extinction under a certain meteorological condition. Their parameters are well-tuned to meet observation data. We show a brief summary of the KM-83 formulae below.

Under a cloudless sky, GSR on a local horizontal plane at the ground at any instant of time, $S$, is given by

$$
\frac{S}{S_{0}}=\left(C+0.7 \times 10^{-f m}\right)(1-i)(1+j),
$$

where $S_{0}$ is the solar radiation on a local horizontal plane at the top of the atmosphere. $S_{0}$ is given by

$$
S_{0}=\left(\frac{1}{r_{\odot}}\right)^{2} I_{0} \cos h
$$

where $r_{\odot}$ is the distance (in astronomical unit) between the Sun and Earth, and $h$ gives the elevation angle of the Sun. We use the solar constant $I_{0}=1.37 \mathrm{~kW} / \mathrm{m}^{2}$.

The right-hand side of equation (1) gives the atmospheric extinction depending on the optical characteristics of the atmosphere under a certain meteorological condition. The parameters are given by

$$
\begin{aligned}
m & =\frac{1}{\cos z} \\
C & =0.21-0.2 \beta \quad(\text { for } \beta \leq 0.3) \\
f & =0.056+0.16 \sqrt{\beta} \\
i & =0.014\left(m+7+2 \log _{10} w\right) \log _{10} w \\
j & =(0.066+0.34 \sqrt{\beta})(A-0.15),
\end{aligned}
$$

where $z$ is the zenith distance of the Sun, $\beta$ is the atmospheric turbidity (Ångström's coefficient), and $w$ is the precipitable water content in the atmosphere. We denote the albedo around the observation site as $A$.

In this study, the parameter $m$ in equation (3), which gives the optical path length of the incident light in the atmosphere (relative to the path length of the incident light from the zenith direction), is slightly modified from the original form of KM-83:

$$
m=\frac{p}{p_{0}} \frac{1}{\cos z},
$$

where $p$ and $p_{0}$ are the on-site surface pressure and the standard pressure $(1013.25 \mathrm{hPa})$, respectively. 
When the hourly ratio of sunshine duration, $\frac{N}{N_{0}}$ ( $N$ and $N_{0}$ are the observed and possible durations of sunshine, respectively), is less than 0.7 , we introduce a multiplier $y$ for estimating GSR under noncloudless skies:

$$
y=1.70 \log _{10}(1.22-1.02 x)+0.521 x+0.846
$$

and

$$
x=\left(1-\frac{N}{N_{0}}\right)-0.4 e^{-3\left(1-N / N_{0}\right)} .
$$

The original idea was suggested in the KM- 83 for estimating daily GSR under noncloudless skies using the daily cloud amount. In this study, we modified the original version of equation (6) by replacing the daily cloud amount by the hourly ratio of sunshine duration. ${ }^{1}$

The precipitable water is not routinely observed at meteorological stations. In this paper, it is estimated from the dew-point temperature $T_{d}$ with an experimental formula (Kondo and Miura 1983)

$$
\begin{array}{ll}
\log _{10} w=0.0350 T_{d}-0.031 & \left(T_{d}<18^{\circ} \mathrm{C}\right) \\
\log _{10} w=0.0222 T_{d}+0.200 & \left(T_{d} \geq 18^{\circ} \mathrm{C}\right) .
\end{array}
$$

Judging from symmetric distribution about the estimated value of $w$ (Fig. 2 of their paper), we consider that there is no systematic bias between estimated and observed values of $w$.

The surface albedo on land areas is assumed to be fixed in 0.2 because it ranges from 0.10 to 0.30 (Lamb 1972). However, the albedo on snowcovered areas has a wider range, such as 0.40 (old thawing snow) to 0.85 (new-fallen snow). The snow-covered land reflects more sunlight to the sky and, as a result, increases the GSR. Besides, errors in the surface albedo directly lead to errors in GSR estimation. Thus, as mentioned later, we exclude snow-season data from our analysis.

\subsection{Criteria for turbidity analysis}

In order to select hourly GSR data suitable for turbidity analysis from the all hourly GSR data, we set the following criteria: (1) Both observed and estimated hourly GSR are available. (2) The sun is never below the horizon during an hour to be ana-

1 However, as described in Section 3.2, we only use cloudless data for our turbidity analysis. Strictly speaking, this multiplier is effective in very limited cases, which satisfy both $\frac{N}{N_{0}}<0.7$ and the observed cloud amount is $<0.5$ ( 10 for totally cloudy). We consider that the results will be unchanged by introducing this multiplier $y$. lyzed. (3) The interpolated cloud amount never exceeds 0.5 (10 for totally cloudy) during a one-hour time section. (4) No snow covers are observed.

The cloud amount is routinely observed every three or six hours, depending on the station. (See Table 1. At stations with $\mathrm{ClObs}=7$, the cloud amount is recorded every three hours. At stations with $\mathrm{ClObs} \leq 4$, the cloud amount is observed every six hours.) The hourly cloud amount data at the stations with $\mathrm{ClObs}=7$ is estimated by linear interpolation of the data at two closest adjoining observation times. However, for data at the stations with $\mathrm{ClObs} \leq 4$, we only use the hourly GSR data at the times when the original cloud amount observation data is available. For convenience, we consider that the cloud amounts ' $0+$ ' and ' $10-$ ' are 0.4 and 9.6, respectively.

Criterion (3) is very stringent to extract the data under cloudless skies. Since we regard the surface albedo as 0.2 in this paper, criterion (4) is necessary to exclude snow-covered seasons.

\subsection{Turbidity estimation}

In order to find the best-fit turbidity at a monthly timescale, we calculate 18 sets of hourly GSR with different turbidity values $(\beta=0.001,0.005,0.01$ to 0.10 by $0.01,0.10$ to 0.20 by 0.02 and 0.25 ) using equation (1). Then we evaluate monthly rootmean-square (rms) misfits between observed and calculated hourly GSRs for every $\beta$ value. A turbidity that achieves the smallest rms misfit in 18 sets gives the 'best-fit turbidity' of a month. Hereafter, we designate it as $\beta^{\prime}$.

\subsection{Validity check in comparison with JMA's turbidity data}

Before discussing the results on the turbidity, we check its validity by comparing time series of the best-fit turbidity data with that of the JMA's turbidity data. However, while our turbidity $\beta^{\prime}$ is given in Angström's coefficient, that of the JMA's is given in Feussner-Dubois' factor, $\tau_{F D}$. Prior to comparison, we need to convert the units.

Angström's coefficient $\beta$ gives the volumetric aerosol content in the air (Ångström 1961). This turbidity cannot be directly linked with the DSR observations. If one would like to estimate $\beta$ from the DSR, some manipulation is required (Yamamoto et al. 1968).

The Feussner-Dubois' factor $\tau_{F D}$ is calibrated at standard pressure from Linke's turbidity factor $\tau_{L}$. Linke's factor $\tau_{L}$ directly links with the atmospheric extinction ratio calculated from DSR observations. 
However, $\tau_{L}$ includes extinction due to both aerosols and water vapor. If one is interested only in aeolian dusts, $\tau_{L}$ might be less suitable than $\beta$ for this purpose.

For unit conversion, stringent accuracy is not required: One reason is that we discuss the turbidity data at a monthly timescale. The atmospheric turbidity shows both diurnal (Yamauchi 1995) and daily variations (Flowers et al. 1969; Roosen et al. 1973); however, observation dates and times of DSR are not coincident with those of GSR used in our turbidity analysis. Another reason is that this conversion is only for validity checks.

There are many known conversion formulae between different turbidity coefficients (e.g., López and Batlles 2004). We use a simple conversion formula (Dogniaux 1974):

$$
\tau_{L}=\left(\frac{85+h}{39.5 e^{-w}+47.4}+0.1\right)+(16+0.22 w) \beta
$$

where $h$ is the Sun's elevation (unit in degree) and $w$ is the precipitable water $(\mathrm{cm})$. The precipitable water $w$ is calculated from equation (7) using the monthly mean vapor pressure $e$. The solar elevation angle $h$ is given by the one at the meridian transit time on the middle day of the month. The best-fit turbidity $\beta^{\prime}$ is converted into Linke's factor $\tau^{\prime}$ using equation (8).
The JMA routinely observes DSR three times a day (each observation is made within \pm 30 minutes at about 9, 12, and $15 \mathrm{~h}$ ) only when no clouds screen the Sun. First, we have to recompile JMA's monthly data at the three observation times. Here, we designate the monthly average turbidity at 9,12 , and $15 \mathrm{~h}$ as $\tau_{9}, \tau_{12}, \tau_{15}$ and the monthly minimum turbidity as $\tau_{9}^{M}, \tau_{12}^{M}, \tau_{15}^{M}$, respectively. The numbers of observation days for each month are given as $N_{9}, N_{12}, N_{15}$. The 'average' $\tau_{a v}$, 'weighted average' $\tau_{\text {wav }}$, and 'minimum' $\tau_{\min }$ turbidity are evaluated as

$$
\begin{aligned}
\tau_{a v} & =\frac{\tau_{9}+\tau_{12}+\tau_{15}}{3} \\
\tau_{\text {wav }} & =\frac{\tau_{9} N_{9}+\tau_{12} N_{12}+\tau_{15} N_{15}}{N_{9}+N_{12}+N_{15}} \\
\tau_{\text {min }} & =\min \left(\tau_{9}^{M}, \tau_{12}^{M}, \tau_{15}^{M}\right) .
\end{aligned}
$$

If some elements of $\left(\tau_{9}, \tau_{12}, \tau_{15}\right)$ are missing, $\tau_{a v}$ is averaged from data at the other observation times.

Differences between $\tau_{L}$ and $\tau_{F D}$ are very small except for stations at high elevation. In this paper, we regard $\tau_{L} \sim \tau_{F D}$ because 13 of 14 DSR stations have elevations of less than $100 \mathrm{~m}$. Therefore, one should pay attention to interpret the results at (47618) Matsumoto (elevation: $610.0 \mathrm{~m}$ ).

Cross correlation coefficients between two time series (Table 2) range from $\sim 0.6$ (at southern stations, such as (47918) Ishigakijima and (47936)

Table 2. Cross-correlation coefficients between time series of our monthly best-fit turbidity $\tau^{\prime}$ and those of JMA's

\begin{tabular}{|c|c|c|c|c|c|c|c|c|c|c|}
\hline \multirow[b]{2}{*}{ ID } & \multirow[b]{2}{*}{ Station } & \multicolumn{4}{|c|}{$\begin{array}{l}\text { (a) JMA-80 operation period } \\
\text { (1991-Replacement) }\end{array}$} & \multirow[b]{2}{*}{ Replacement } & \multicolumn{4}{|c|}{$\begin{array}{l}\text { (b) JMA-95 operation period } \\
\text { (Replacement-2005) }\end{array}$} \\
\hline & & $\tau_{a v}$ & $\tau_{w a v}$ & $\tau_{\min }$ & $\mathrm{N}$ & & $\tau_{a v}$ & $\tau_{w a v}$ & $\tau_{\min }$ & $\mathrm{N}$ \\
\hline 412 & Sapporo & 0.89 & 0.88 & 0.78 & 60 & Dec. 1997 & 0.83 & 0.83 & 0.77 & 58 \\
\hline 420 & Nemuro & 0.71 & 0.72 & 0.73 & 77 & Jan. 1998 & 0.80 & 0.81 & 0.83 & 82 \\
\hline 582 & Akita & 0.80 & 0.80 & 0.68 & 65 & Feb. 1998 & 0.77 & 0.78 & 0.75 & 53 \\
\hline 585 & Miyako & 0.79 & 0.79 & 0.67 & 83 & Feb. 1998 & 0.93 & 0.93 & 0.92 & 91 \\
\hline 600 & Wajima & 0.74 & 0.75 & 0.76 & 58 & Feb. 1996 & 0.72 & 0.73 & 0.72 & 92 \\
\hline 618 & Matsumoto & 0.84 & 0.83 & 0.82 & 72 & Feb. 1997 & 0.92 & 0.92 & 0.91 & 103 \\
\hline 646 & Tateno & 0.90 & 0.90 & 0.84 & 80 & Jan. 1998 & 0.95 & 0.95 & 0.91 & 91 \\
\hline 744 & Yonago & 0.79 & 0.78 & 0.57 & 101 & Dec. 1999 & 0.86 & 0.86 & 0.80 & 64 \\
\hline 778 & Shionomisaki & 0.94 & 0.94 & 0.92 & 96 & Feb. 1999 & 0.87 & 0.87 & 0.85 & 82 \\
\hline 807 & Fukuoka & 0.77 & 0.77 & 0.78 & 94 & Jan. 1999 & 0.91 & 0.91 & 0.84 & 80 \\
\hline 827 & Kagoshima & 0.73 & 0.74 & 0.76 & 94 & Jan. 1999 & 0.75 & 0.75 & 0.76 & 80 \\
\hline 898 & Shimizu & 0.86 & 0.85 & 0.85 & 95 & Jan. 1999 & 0.87 & 0.87 & 0.91 & 81 \\
\hline 918 & Ishigakijima & 0.71 & 0.73 & 0.77 & 65 & Jan. 2000 & 0.66 & 0.66 & 0.67 & 51 \\
\hline 936 & Naha & 0.72 & 0.73 & 0.71 & 83 & Dec. 1999 & 0.61 & 0.63 & 0.47 & 49 \\
\hline
\end{tabular}
monthly turbidities, $\tau_{a v}, \tau_{w a v}, \tau_{\min }$, at 14 DSR stations. The analysis periods are (a) the JMA-80 operation period (from 1991 to the replacement with the JMA-95-type instruments) and (b) the JMA-95 operation period (from the replacement to 2005). The last columns (marked ' $\mathrm{N}$ ') indicate the number of months used in the correlation analysis. 
Naha) to $>0.9$ (at (47646) Tateno). Despite the use of a simple conversion formula from $\beta^{\prime}$ to $\tau^{\prime}$ (equation (8)), high correlation coefficients are obtained at most stations. This result indicates that the bestfit turbidity is practical for describing the real atmospheric turbidity. There is no significant difference in trend between the different types of meteorological instrument, the JMA-80 and JMA-95. However, turbidities estimated with the JMA-80type instruments tend to be more unstable than those estimated with the JMA-95-type instruments at some stations. Not shown in this paper, but the time series of $\tau_{a v}$ is very similar to that of $\tau_{w a v}$. Time variation of $\tau^{\prime}$ fairly synchronizes $\tau_{\text {wav }}$ and $\tau_{\min }$, and the values of $\tau^{\prime}$ are closer to $\tau_{\min }$ than to $\tau_{\text {wav }}$.

\section{Results on best-fit monthly turbidity}

\subsection{Time-variation of turbidity at 67 GSR stations}

We apply our method to estimate the best-fit monthly turbidity $\beta^{\prime}$ at 67 GSR stations in Japan. At most stations, seasonal variation patterns in $\beta^{\prime}$ are detected. Some examples of time series of bestfit turbidity from 1999 to 2006 are shown in Fig. 1. At stations where much human and industrial activities take place (e.g., (47662) Tokyo, (47772) Osaka, etc.), $\beta^{\prime}$ shows large variations at high values. On the other hand, at stations far apart from active anthropogenic activity regions (e.g., isolated islands, (47971) Chichijima and (47991) Minamitorishima, or stations located at capes, (47898) Shimizu), $\beta^{\prime}$ tends to be stable at low values.

Some temporal changes in atmospheric turbidity are also found in a small area. Such local phenomena are hardly detectable by sparse distribution of the stations for atmospheric turbidity observation. Synchronization of temporal increases/decreases in $\beta^{\prime}$ among neighborhood stations implies that the best-fit turbidity detects real phenomena in the atmosphere. In Fig. 1, we show two examples of time variation in $\beta^{\prime}$ at a regional scale by extracting neighborhood stations: four stations in Hokkaido region ((47406) Rumoi, (47407) Asahikawa, (47412) Sapporo and (47421) Suttsu) and six stations in Kyushu-Shikoku region ((47813) Saga, (47815) Oita, (47817) Nagasaki, (47819) Kumamoto, (47887) Matsuyama and (47893) Kochi). These stations are geographically distributed within radii of $120 \mathrm{~km}$ and $180 \mathrm{~km}$, respectively. Spatial distribution of the synchronized turbidity variations helps us to understand the spatial extent of pollutants in the air such as aerosols.

Interestingly, we can also observe strong synchronized events of turbidity increase in Fig. 1. One of them is observed at many northern stations in May 2003 (Fig. 1c) and another event is observed at most central and western stations in spring to summer of 2006 (Fig. 1d). Snapshots of geographical distribution of $\beta^{\prime}$ are shown in Figs. 2,3 , respectively. These increases in $\beta^{\prime}$ are subnationwide phenomena.

The event in 2003 corresponds to a forest fire that occurred in West Siberia. Soot emitted in the air was transported by westerly winds and densely covered a vast area of northern Japan (Japan Meteorological Agency, 2004). Smoke particles were detected not only in Japan (by lidar observation (Murayama et al. 2004) and chemical analysis of the atmosphere (Kaneyasu et al. 2007)) but also in Europe (Mattis et al. 2003). Damoah et al. (2004) detected burning areas east of Lake Baikal on May 14 in satellite images. Their numerical simulation revealed that the emissions from the burning areas arrived in east Asia within a few days.

The event in 2006 corresponds to frequent Asian dust (yellow sand) events, aeolian dust blown from dry areas in northern China. Diminution of solar radiation owing to an increase in the amount of floating sand particles is commonly observed in spring to summer in Japan. In 2006, sand particles at a density higher than in previous years caused a strong reduction in solar radiation. In fact, dust storm observation in China also supports this statement: Spring 2006 was the most frequent dust

Fig. 1. Examples of time series of best-fit monthly turbidity $\beta^{\prime}$. The vertical axis indicates the Ångström's turbidity coefficient. The five-digit numbers on the left of the time series indicate station IDs (Table 1). Open and solid squares indicate observations with the JMA-80- and JMA-95-type instruments, respectively. Missing monthly values imply that $\beta^{\prime}$ of the month can not be determined because the criteria for analysis (described in Section 3.2) are not satisfied. Two vertical lines are placed on May 2003 (in time series (c)) and April 2006 (in time series (d)) when a forest fire in West Siberia and severe Asian dust events occurred, respectively (see text). 
(a) Anthropogenic activity regions

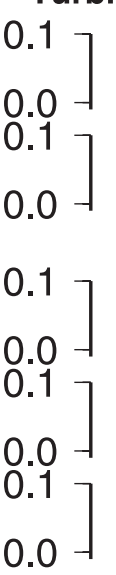

47662 47772

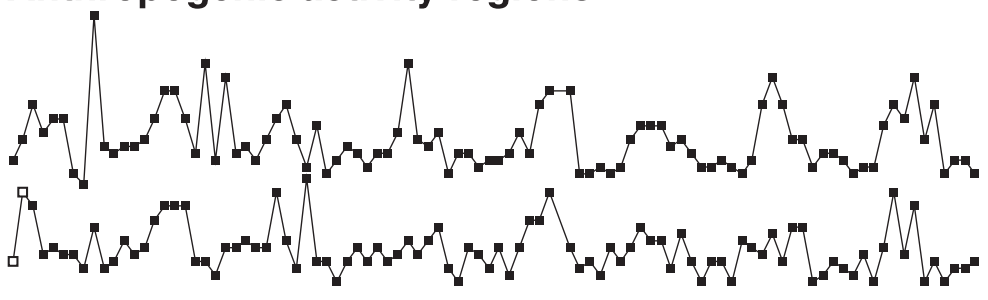

(b) Isolated islands / Capes

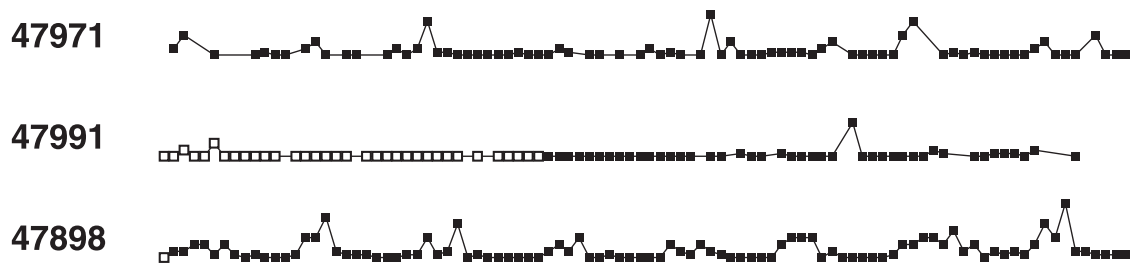

(c) Neighborhood stations (Hokkaido region)

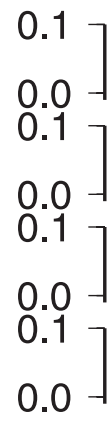

47406

47407

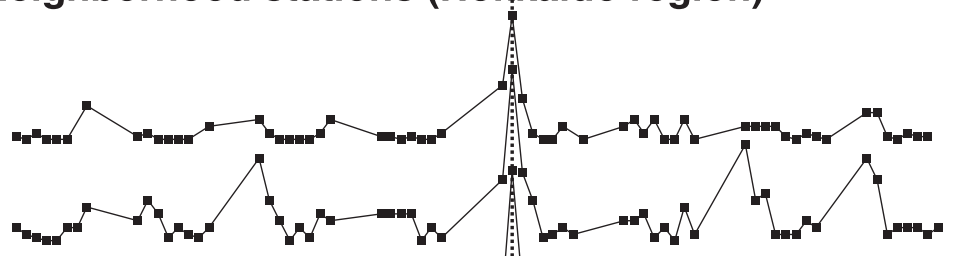

47412

47421
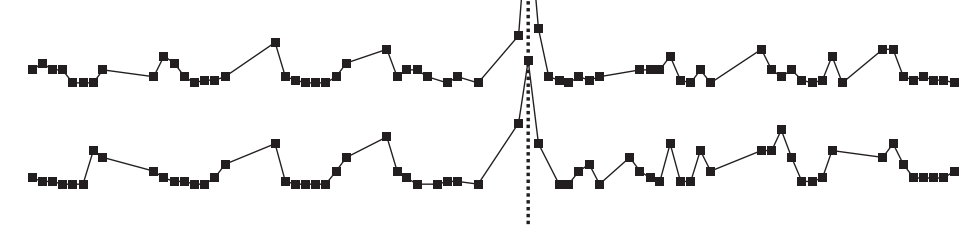

(d) Neighborhood stations (Kyushu - Shikoku region)

$\left.\begin{array}{l}0.1 \\ 0.0 \\ 0.1 \\ 0.0\end{array}\right]$

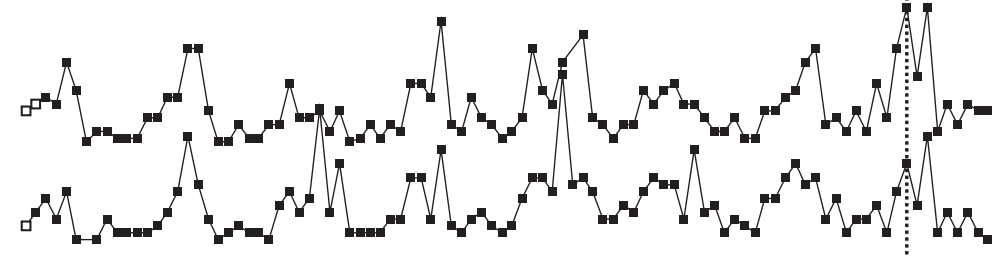

0.1

0.0

0.1

0.0

0.1

0.0

47813

47815

47817
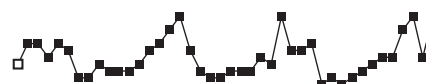<smiles>C1CC1C1CC1</smiles><smiles>C1CCCCC1</smiles>

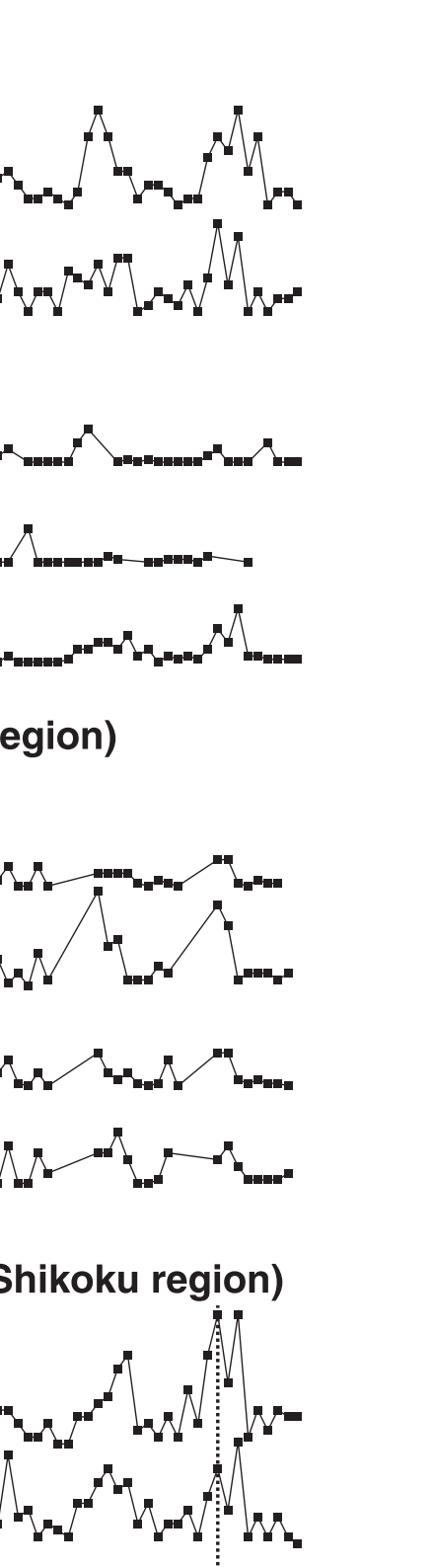

$\left.\begin{array}{l}0.1 \\ 0.0\end{array}\right]$

47819

47887

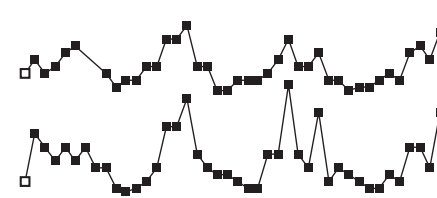

1

\section{3}

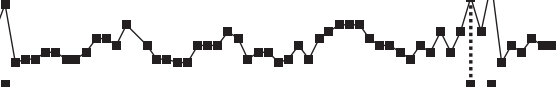

$\begin{array}{lllllllllll}1997 & 1998 & 1999 & 2000 & 2001 & 2002 & 2003 & 2004 & 2005 & 2006 & 2007\end{array}$ 


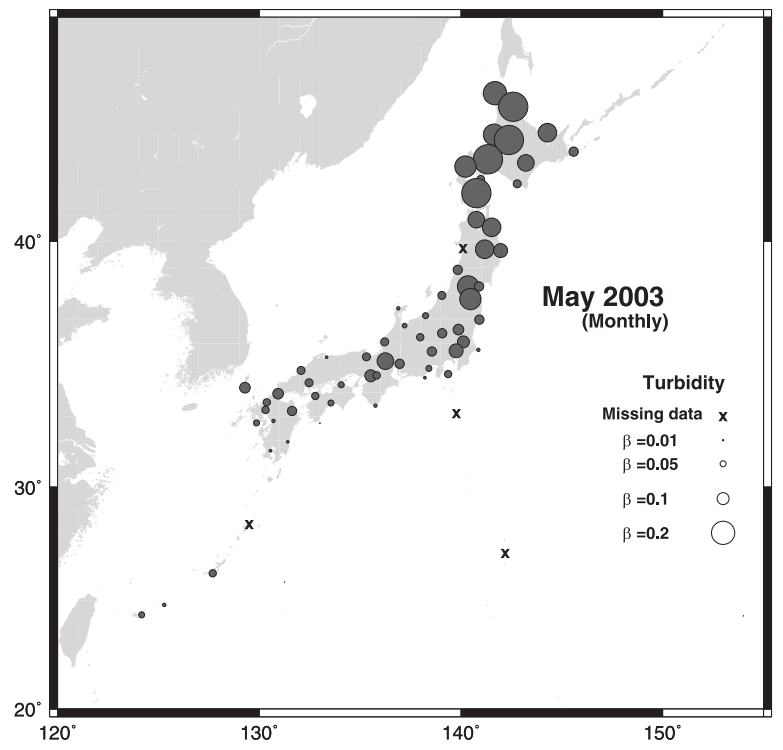

Fig. 2. Geographical distribution of the best-fit turbidity $\beta^{\prime}$ on May 2003 . The value is indicated by the radius of the circle.

storm seasons in the previous ten years in northeast Asia (Yang et al. 2008). Satellite images clearly depicted a severe dust storm covering over northeast China during April 14-16 (Zha and Li 2007).

In Fig. 1, nonsynchronized spikes are also observed. It is uncertain whether such features are attributed to real phenomena in the air. Such spikes might also include erroneous observations. For example, at (47595) Fukushima, anomalous high turbidity $\left(\beta^{\prime}=0.25\right)$ values were obtained for four successive months in 1999 (not shown).

As explained in Section 3.2, GSR data in snowcovered seasons are excluded from the analysis. Therefore, best-fit turbidity is unavailable in winter at stations in northern Japan (e.g., Fig. 1c).

\subsection{Seasonal variation and annual mean of turbidity at 67 GSR stations}

The annual mean and averaged seasonal variation of best-fit monthly turbidity at 67 GSR stations (averaged for 1999-2006) are summarized in Table 3. The highest turbidity occurs in spring to summer at most stations. The geographical distribution of the annual mean of turbidity is also shown in Fig. 4. High turbidity is observed at large cities along the Pacific coast.

At some inland stations located in basins, such as (47407) Asahikawa, (47588) Yamagata, and (47638) Kofu, the annual means tend to be slightly

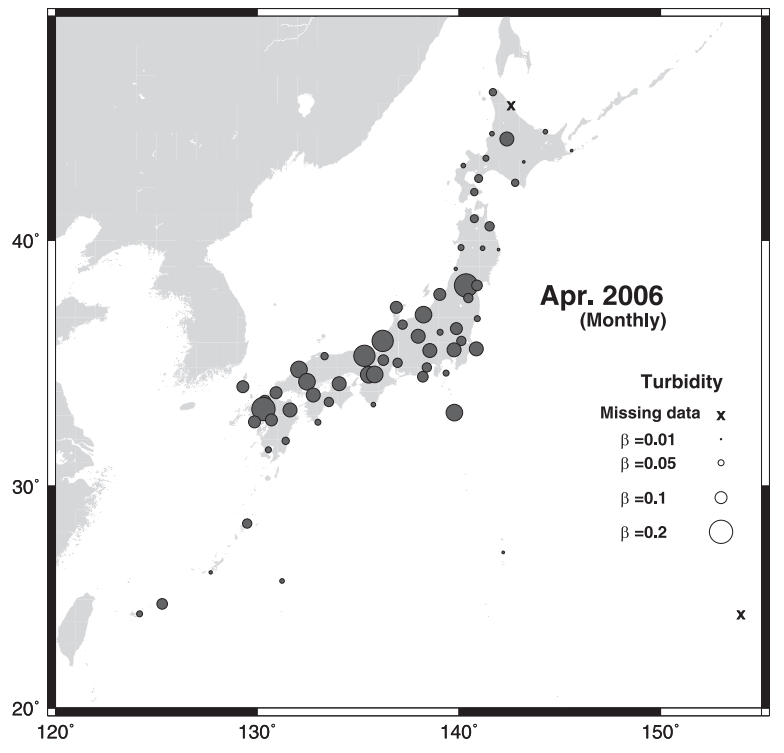

Fig. 3. As in Fig. 2 except for April 2006.

larger than those in the surrounding stations. Further studies are necessary to obtain a valid conclusion on this issue. We note that (47595) Fukushima also has high annual mean values, but the data may have been affected by doubtful monthly turbidity data obtained in 1999 (Section 4.1).

\section{Statistical results}

\subsection{Fitting errors of hourly GSR with best-fit monthly turbidity}

First, we check the fitting errors of hourly GSR calculated with the best-fit monthly turbidity. The misfit is evaluated as O-C (observed hourly GSR minus calculated hourly GSR). We calculate bias and rms misfits from all hourly O-Cs for every month and for every station. We use a term 'case' for a group of hourly GSR observations on the same month at the same station. The same analysis criteria in Section 3.2 are used for the analysis.

Figure 5 shows a summary of the fitting error statistics. The total case number of this study is $N=$ $5631 .^{2}$ The misfit bias is very small (Fig. 5a). Most cases lie in less than $0.02 \mathrm{MJ} / \mathrm{m}^{2} / \mathrm{h}\left(5.6 \mathrm{~W} / \mathrm{m}^{2}\right)$.

26432 cases $(=67$ stations $\times 12$ months $\times 8$ years $)$ are expected at maximum, but 801 cases are excluded from the turbidity analysis because no GSR observation was made throughout a month (e.g., The JMA ceased GSR observation at (47402) Kitamiesashi on September 2004.) or no hourly GSR observation satisfies the criteria on turbidity analysis throughout a month. 
Table 3. Annual mean and averaged seasonal variations of best-fit turbidity at 67 GSR stations (averaged for 19992006). In the case of missing monthly data (marked '-'), the annual mean values are evaluated from data of the other months. Annual mean values in italics indicate some monthly averaged values are missing. Averaged monthly values in italics indicate the number of years used for calculating the averages is less than three.

\begin{tabular}{|c|c|c|c|c|c|c|c|c|c|c|c|c|c|c|}
\hline ID & Station & Annual & Jan & $\mathrm{Feb}$ & Mar & Apr & May & June & July & Aug & Sept & Oct & Nov & Dec \\
\hline 401 & Wakkanai & 0.032 & - & - & .14 & .032 & .051 & .032 & .009 & .003 & .003 & .019 & .032 & .005 \\
\hline 402 & Kitamiesashi & 0.021 & - & - & - & .034 & .060 & .027 & .015 & .006 & .003 & .009 & .030 & .005 \\
\hline 406 & Rumoi & 0.014 & - & - & - & .026 & .037 & .013 & .009 & .003 & .002 & .014 & .021 & .001 \\
\hline 407 & Asahikawa & 0.035 & - & - & - & .074 & .075 & .042 & .018 & .012 & .012 & .023 & .023 & - \\
\hline 409 & Abashiri & 0.010 & .003 & - & .007 & .018 & .035 & .006 & .003 & .002 & .004 & .010 & .007 & .012 \\
\hline 412 & Sapporo & 0.021 & - & - & .050 & .036 & .055 & .024 & .015 & .004 & .002 & .008 & .015 & .004 \\
\hline 417 & Obihiro & 0.030 & - & .010 & .100 & .050 & .051 & .028 & .016 & .013 & .013 & .019 & .021 & .006 \\
\hline 420 & Nemuro & 0.009 & .00 & .003 & .020 & .034 & .026 & .010 & .006 & .002 & .002 & .004 & .004 & .002 \\
\hline 421 & Suttsu & 0.024 & - & - & .055 & .039 & .041 & .023 & .019 & .003 & .004 & .022 & .033 & .001 \\
\hline 423 & Muroran & 0.017 & .003 & .025 & .039 & .033 & .025 & .010 & .011 & .007 & .003 & .011 & .022 & .010 \\
\hline 426 & Urakawa & 0.015 & .002 & .015 & .036 & .037 & .028 & .020 & .006 & .006 & .002 & .012 & .008 & .008 \\
\hline 430 & Hakodate & 0.026 & - & .020 & .057 & .050 & .054 & .019 & .015 & .009 & .006 & .016 & .039 & .004 \\
\hline 575 & Aomori & 0.030 & - & - & .100 & .058 & .042 & .024 & .021 & .012 & .007 & .018 & .017 & .005 \\
\hline 581 & Hachinohe & 0.024 & .012 & .015 & .051 & .054 & .051 & .021 & .018 & .014 & .008 & .016 & .024 & .006 \\
\hline 582 & Akita & 0.012 & - & .005 & .022 & .043 & .014 & .025 & .003 & .004 & .002 & .003 & .005 & .002 \\
\hline 584 & Morioka & 0.027 & .002 & - & .049 & .047 & .047 & .034 & .026 & .019 & .012 & .027 & .017 & .022 \\
\hline 585 & Miyako & 0.011 & .002 & .009 & .022 & .026 & .031 & .012 & .012 & .004 & .002 & .010 & .002 & .001 \\
\hline 587 & Sakata & 0.020 & .010 & .040 & .044 & .040 & .027 & .021 & .009 & .008 & .004 & .017 & .011 & .010 \\
\hline 588 & Yamagata & 0.043 & .020 & .020 & .058 & .090 & .068 & .065 & .044 & .059 & .018 & .027 & .014 & .040 \\
\hline 590 & Sendai & 0.022 & .002 & .003 & .036 & .049 & .036 & .052 & .041 & .025 & .0 & .006 & .001 & .002 \\
\hline 595 & Fukushima & 0.058 & .009 & .035 & .069 & .081 & .075 & .090 & .100 & .090 & .071 & .029 & .025 & .023 \\
\hline 598 & Onahama & 0.024 & .007 & .018 & .044 & .048 & .035 & .041 & .026 & .043 & .0 & .008 & .007 & .004 \\
\hline 600 & Wajima & 0.028 & .00 & .024 & .055 & .060 & .039 & .055 & .037 & .016 & .019 & .010 & .007 & .008 \\
\hline 604 & Niigata & 0.022 & .017 & .014 & .045 & .056 & .028 & .021 & .009 & .013 & .008 & .010 & .014 & .026 \\
\hline 607 & Toyama & 0.027 & .004 & .011 & .050 & .062 & .035 & .061 & .042 & .020 & .0 & .009 & .007 & .005 \\
\hline 612 & Takada & 0.029 & .00 & .010 & .055 & .062 & .030 & .049 & .024 & .043 & .0 & .014 & .019 & .014 \\
\hline 615 & Utsunomiya & 0.042 & .017 & .035 & .057 & .077 & .066 & .075 & .056 & .047 & .024 & .024 & .016 & .014 \\
\hline 616 & Fukui & 0.039 & .01 & .038 & .057 & .081 & .040 & .062 & .046 & .024 & .024 & .018 & .018 & .039 \\
\hline 618 & Matsumoto & 0.025 & .00 & .013 & .030 & .056 & .041 & .042 & .045 & .022 & .018 & .013 & .007 & .006 \\
\hline 624 & Maebashi & 0.042 & .012 & .029 & .058 & .070 & .060 & .085 & .038 & .074 & .028 & .022 & .013 & .014 \\
\hline 636 & Nagoya & 0.028 & .00 & .016 & .044 & .060 & .054 & .064 & .032 & .022 & .014 & .011 & .009 & .006 \\
\hline 638 & Kofu & 0.047 & .024 & .034 & .049 & .071 & .071 & .089 & .042 & .064 & .0 & .033 & .026 & .028 \\
\hline 646 & Tateno & 0.038 & .016 & .030 & .056 & .068 & .062 & .068 & .032 & .045 & .034 & .021 & .014 & .015 \\
\hline 648 & Choshi & 0.019 & .011 & .017 & .044 & .047 & .034 & .031 & .012 & .011 & .003 & .005 & .008 & .008 \\
\hline 655 & Omaezaki & 0.017 & .006 & .009 & .031 & .039 & .026 & .030 & .023 & .013 & .008 & .008 & .008 & .004 \\
\hline 656 & Shizuoka & 0.031 & .00 & .018 & .039 & .056 & .056 & .067 & .044 & .033 & .022 & .015 & .011 & .006 \\
\hline 662 & Tokyo & 0.069 & .039 & .056 & .098 & .12 & .10 & .090 & .064 & .071 & .062 & .059 & .041 & .035 \\
\hline 675 & Oshima & 0.022 & .005 & .017 & .040 & .036 & .045 & .043 & .023 & .016 & .019 & .010 & .009 & .007 \\
\hline 678 & Hachijojima & 0.024 & .018 & .026 & .040 & .060 & .023 & .012 & .009 & .013 & .040 & .017 & .015 & .017 \\
\hline 744 & Yonago & 0.012 & .004 & .013 & .020 & .026 & .019 & .014 & .013 & .009 & .004 & .007 & .010 & .003 \\
\hline 750 & Maizuru & 0.050 & .022 & .033 & .071 & .091 & .062 & .081 & .091 & .036 & .019 & .033 & .028 & .027 \\
\hline 755 & Hamada & 0.028 & .016 & .029 & .068 & .058 & .044 & .030 & .019 & .015 & .009 & .017 & .018 & .014 \\
\hline 761 & Hikone & 0.077 & .031 & .063 & .11 & .13 & .11 & .12 & .091 & .073 & .050 & .047 & .046 & .057 \\
\hline 762 & Shimonoseki & 0.040 & .031 & .039 & .064 & .062 & .061 & .065 & .032 & .022 & .025 & .022 & .027 & .024 \\
\hline 765 & Hiroshima & 0.048 & .034 & .048 & .076 & .084 & .071 & .066 & .057 & .041 & .027 & .023 & .021 & .022 \\
\hline 772 & Osaka & 0.057 & .054 & .056 & .084 & .088 & .065 & .098 & .057 & .036 & .025 & .042 & .041 & .043 \\
\hline 778 & Shionomisaki & 0.016 & .007 & .014 & .026 & .028 & .028 & .024 & .027 & .013 & .004 & .007 & .007 & .004 \\
\hline 780 & Nara & 0.056 & .026 & .044 & .079 & .079 & .071 & .11 & .100 & .051 & .048 & .024 & .018 & .018 \\
\hline 800 & Izuhara & 0.040 & .021 & .033 & .066 & .066 & .069 & .085 & .028 & .021 & .025 & .028 & .019 & .016 \\
\hline 807 & Fukuoka & 0.031 & .017 & .023 & .043 & .053 & .050 & .071 & .028 & .028 & .023 & .016 & .011 & .011 \\
\hline
\end{tabular}


Table 3 (continued)

\begin{tabular}{|c|c|c|c|c|c|c|c|c|c|c|c|c|c|c|}
\hline ID & Station & Annual & Jan & Feb & Mar & Apr & May & June & July & Aug & Sept & Oct & Nov & D \\
\hline 813 & Saga & 0.055 & .037 & .045 & .089 & .086 & .087 & .12 & .046 & .048 & .029 & .027 & .029 & \\
\hline 815 & Oita & 0.059 & .033 & .053 & .081 & .085 & .087 & .12 & .067 & .050 & .044 & .031 & .029 & \\
\hline 317 & Nagasaki & 0.036 & .039 & .042 & .059 & .062 & .054 & .058 & .023 & .013 & .016 & .016 & .021 & \\
\hline 819 & Kumamoto & 0.034 & .033 & .035 & .054 & .060 & .054 & .061 & .020 & .021 & .013 & .016 & .021 & \\
\hline 827 & Kagoshima & 0.024 & .012 & .019 & .031 & .034 & .039 & .041 & .049 & .012 & .017 & .017 & .011 & \\
\hline 830 & Miyazaki & 0.026 & .019 & .026 & .047 & .044 & .041 & .040 & .014 & .019 & .019 & .013 & .016 & \\
\hline 887 & Matsuyama & 0.043 & .026 & .045 & .076 & .074 & .066 & .077 & .049 & .033 & .024 & .017 & .010 & \\
\hline 391 & Takamatsu & 0.041 & .031 & .043 & .062 & .064 & .049 & .053 & .036 & .028 & .036 & .029 & .035 & \\
\hline 893 & Kochi & 0.029 & .013 & .026 & .049 & .049 & .048 & .048 & .029 & .020 & .022 & .019 & .013 & \\
\hline 398 & Shimizu & 0.011 & .003 & .008 & .021 & .024 & .024 & .027 & .012 & .005 & .005 & .002 & .003 & \\
\hline 909 & Naze & 0.045 & .043 & .052 & .060 & .069 & .090 & .009 & .035 & .058 & .016 & .022 & .034 & .0 \\
\hline 918 & Ishigakijima & 0.014 & .013 & .011 & .028 & .039 & .026 & .004 & .004 & .015 & .010 & .009 & .011 & \\
\hline 927 & Miyakojima & 0.020 & .014 & .021 & .037 & .046 & .035 & .017 & .001 & .018 & .017 & .016 & .011 & \\
\hline 936 & Naha & 0.020 & .026 & .022 & .041 & .039 & .030 & .003 & .024 & .020 & .006 & .006 & .017 & \\
\hline 945 & Minamidaitojima & 0.013 & .012 & .008 & .058 & .013 & .022 & .008 & .002 & .008 & .009 & .009 & .008 & \\
\hline 971 & Chichijima & 0.006 & .003 & .008 & .020 & .010 & .003 & .003 & .013 & .001 & .011 & .001 & .002 & \\
\hline 991 & Minamitorishima & 0.003 & .002 & .002 & .003 & .001 & .002 & .005 & .001 & .001 & .011 & .002 & .002 & \\
\hline
\end{tabular}

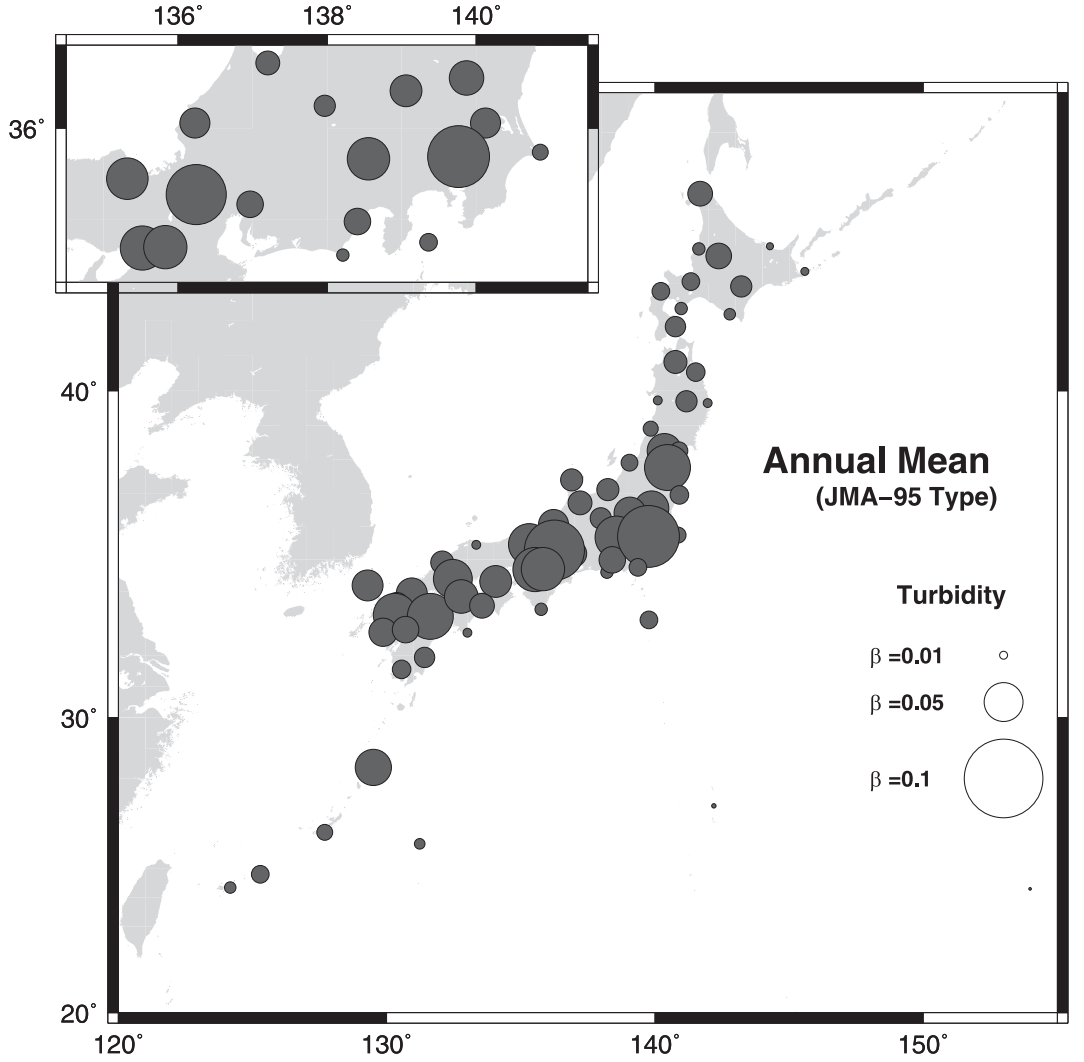

Fig. 4. Geographical distribution of the annual mean of our best-fit turbidity $\beta^{\prime}$. The value is indicated by the radius of the circle. The inset on the upper-left corner shows the same result, but at a magnified scale for central Japan. 

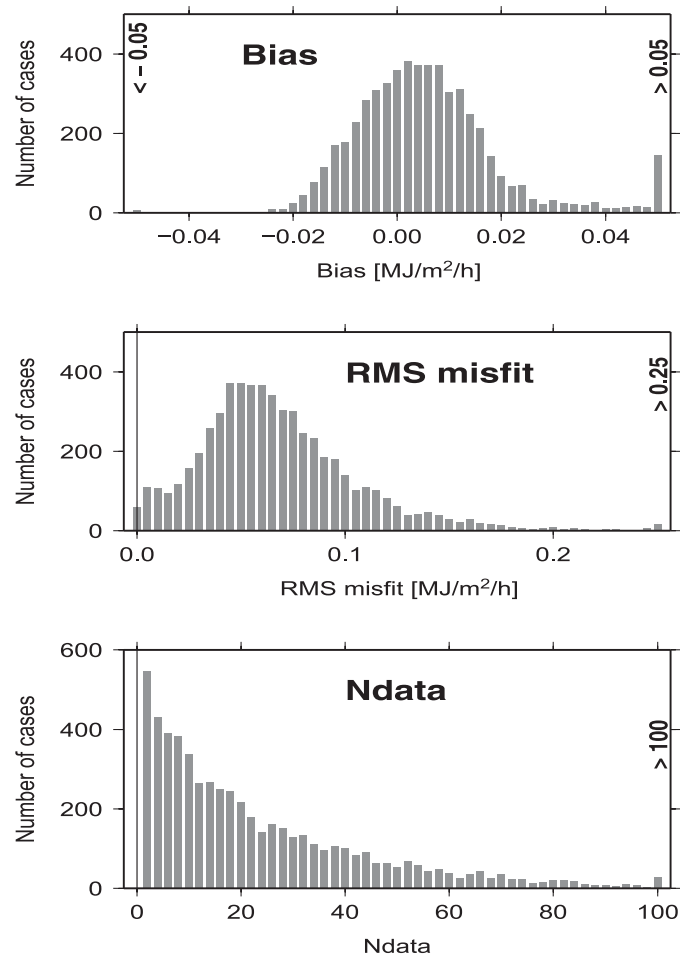

Fig. 5. Histograms of statistics on fitting errors of hourly GSR with the best-fit monthly turbidity. The vertical axis for each panel shows the number of cases (total case number $N=5631$ ). (a) Bias and (b) RMS of the O-C misfits, and (c) $N_{\text {data }}$ (see Section 5.1).

However, its distribution is asymmetric about zero: The number of cases with positive biases is slightly greater than that with negative ones. Distribution of RMS misfits has a peak at approximately $0.05 \mathrm{MJ} / \mathrm{m}^{2} / \mathrm{h} \quad\left(14 \mathrm{~W} / \mathrm{m}^{2}\right)$ (Fig. $\left.5 \mathrm{~b}\right) ; 4796$ cases $(85.2 \%)$ lie in $<0.1 \mathrm{MJ} / \mathrm{m}^{2} / \mathrm{h}\left(28 \mathrm{~W} / \mathrm{m}^{2}\right)$.

The number of hourly data that satisfies the analysis criteria per case, $N_{\text {data }}$, has a wide range of distribution (Fig. 5c); 2086 cases $(37.0 \%)$ of best-fit turbidities from data with $N_{\text {data }} \leq 10$, which means less than 10 hourly GSRs, are used for estimating a best-fit monthly turbidity.

\subsection{Expected errors in hourly GSR calculation with seasonal turbidity variations}

Next, we apply seasonal turbidity variations to hourly GSR calculation. It is obvious that less improvement is expected at stations where seasonal turbidity variations are very small. Thus, we take (47662) Tokyo as an example. We evaluate rms misfits for the five sets of GSR calculation with fixed turbidities $(\beta=0.04,0.07$, and 0.12$)$ and variable monthly turbidities (average seasonal turbidity variations in Table 3 and the best-fit monthly turbidity $\beta^{\prime}$ ). The values of $\beta=0.04$ and 0.12 approximately correspond to the minimum and maximum seasonal turbidity variations, while that of $\beta=0.07$ approximately gives the annual mean. The results are shown in Fig. 6.

The GSRs with the best-fit monthly turbidity give the smallest rms misfits. If a turbidity value is fixed throughout a year, the annual mean value is recommended. The rms misfits for $\beta=0.04$ and 0.12 seasonally increase in antiphase. The GSRs with the seasonal turbidity variation are better than those with a constant turbidity.

\section{Discussion}

\subsection{Best-fit turbidity}

In this paper, the best-fit monthly turbidity has been estimated from the hourly GSR data. The real turbidity varies more rapidly with time (for example, diurnal variations (Yamauchi 1995), washout effects after heavy rainfalls (Yamamoto et al. 1968), or abrupt changes with a cold front passage (Flowers et al. 1969)). If hourly GSR observation data under cloudless skies are available throughout a few successive days, our method could be used to detect such temporal turbidity changes at a practical level.

We suspect that our $\beta^{\prime}$ estimation tends to be underestimated. The obtained best-fit turbidity $\beta^{\prime}$ tends to be smaller than the plausible turbidity values found in the literature (e.g., Kondo and Miura 1983; Dogniaux 1994). Moreover, the distribution of $\mathrm{O}-\mathrm{C}$ bias is asymmetric about zero, in excess in the number of cases with positive biases. If the observed GSR is larger than the maximum GSR, that is achieved with the minimum value of $\beta^{\prime}$ (i.e., 0.001 in our analysis (see Section 3.3)), the $\mathrm{O}-\mathrm{C}$ misfit has a positive value, being a potential source for the asymmetric distribution. Thus, the asymmetric distribution of $\mathrm{O}-\mathrm{C}$ bias implies that, for some hourly data, $\beta^{\prime}$ might be less than 0.001 .

One possible reason for this underestimation is the difference in theoretical frameworks, which GSR calculation schemes refer to. The KM-83 formulae are based on the theoretical framework of Robinson (1966). If solar radiation formulae are based on different sets of solar radiation spectrum and physical parameters, solar radiations given by these formulae also differ. As reported by Kondo 

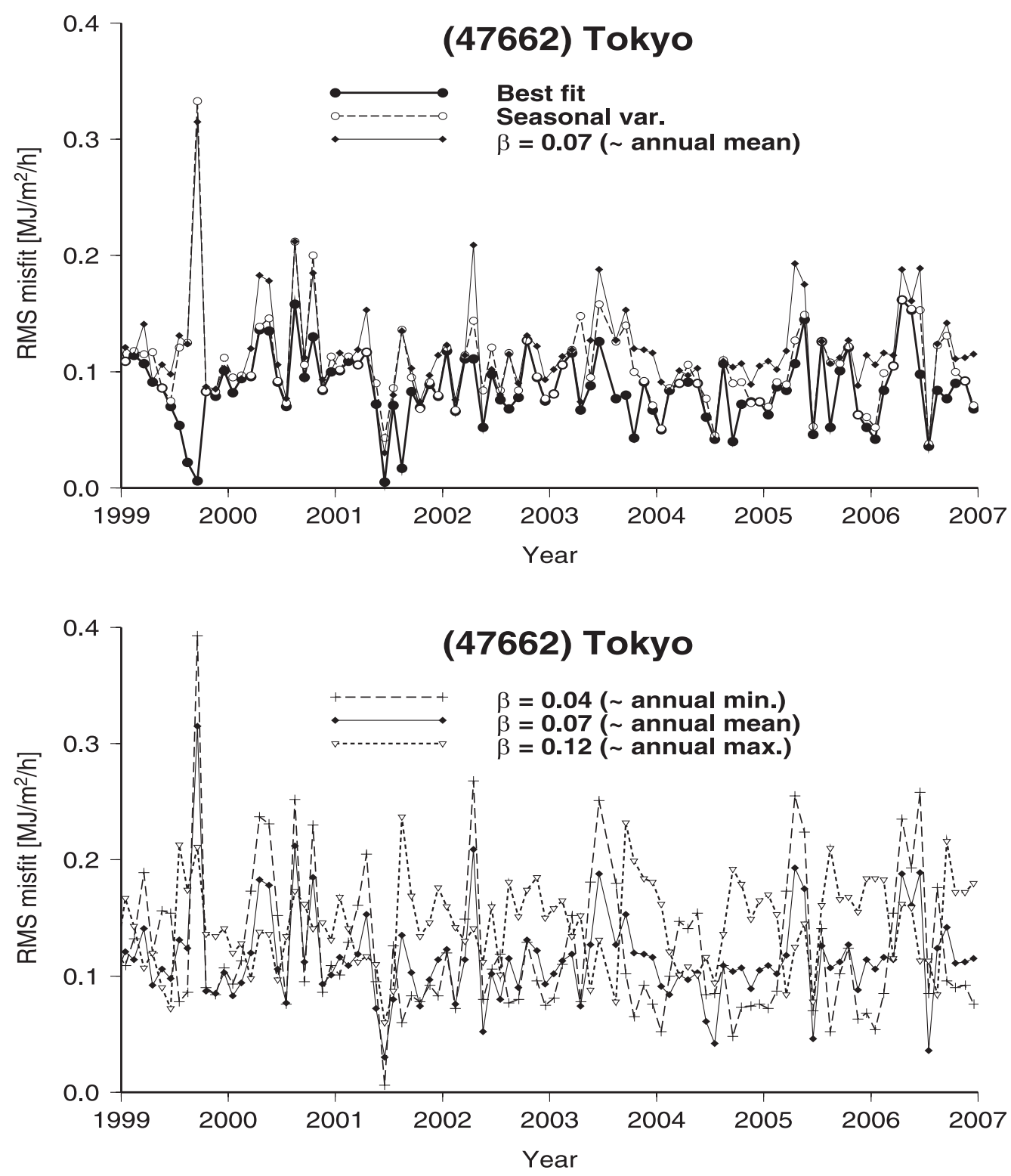

Fig. 6. Monthly RMS misfits of hourly GSR calculation with various turbidity values. (a) Given turbidities are the best-fit monthly turbidity (filled circle), the seasonal variations given in Table 3 (open circle), and $\beta=0.07$ (diamond). (b) Given turbidities are $\beta=0.04$ (cross), 0.07 (diamond), and 0.12 (triangle). Results of $\beta=0.07$ appear in both panels for comparison.

(1994), the turbidity estimated from the formulae based on the framework of Robinson tends to be smaller than that based on the framework of Yamamoto et al. (1968) by about 0.02 to 0.04 . Another reason is surface albedo. We assume that the surface albedo is 0.2 ; however, the real albedo varies with time and space. If the real albedo is greater, it leads to a larger calculated GSR. As a result, atmospheric turbidity is artificially underestimated.

The obtained turbidity is also affected by several factors, such as errors (both random and systematic) in GSR observation, incorrectly estimated meteorological parameters (e.g., the precipitable water), and incorrectly interpolated meteorological data (e.g., the cloud amount at a certain instant), 
etc. We consider that the best-fit turbidity is insensitive to random errors to some extent because the best-fit turbidity is determined from a group of data during a month. If we use fine-tuned parameters and data sets for GSR calculation, we could obtain more stable and accurate turbidity.

Turbidity at inland stations tends to be larger than that at surrounding stations, but their differences are not so large. Further analysis is required to resolve this issue.

\subsection{Merits of using hourly cloudless GSR data for turbidity estimation}

In this paper, we use hourly GSR data, instead of daily GSR, under cloudless skies. Using hourly GSR data has an advantage for statistical treatments because more observation data are available. That is, we can easily collect cloudless data throughout an hour; however, we can barely collect cloudless data throughout a daytime.

In this study, owing to the improvement of meteorological instruments, we can use accurate GSR data. Thus, the turbidity can be estimated with better quality. Since observed GSR is also affected from optical properties of clouds, choosing cloudless data has an advantage for accurate estimation of atmospheric turbidity. About 30 years ago, Murai and Yamauchi (1975) carried out a similar type of analysis using monthly GSR observation data and obtained effective transmissivity. However, they did not arrive at a valid conclusion because of the poor quality of the GSR data obtained using the Robitzsch-type pyrheliometers.

Their effective transmissivity $\tau=a+b$ was determined from the coefficients of a regression line in the form of

$$
\frac{S_{c}}{S_{0}}=a+b \frac{N}{N_{0}},
$$

where $S_{c}$ is the GSR on a local horizontal plane at the ground under both cloudless and noncloudless skies, $S_{0}$ is the solar radiation at the top of the atmosphere, and $N$ and $N_{0}$ are the observed and possible durations of sunshine, respectively. Large dispersion in GSR under cloudy skies might also degrade their estimation on the effective transmissivity.

\subsection{Potential application of our turbidity data}

If we use 67 GSR observation stations, we can monitor atmospheric turbidity with a much higher geographical resolution. Our method has a potential to compensate for the sparseness of the current
DSR observation network (Sapporo, Tateno, Fukuoka and Ishigakijima) for depicting local atmospheric turbidity variations.

Local variation of atmospheric turbidity is also important for studies on aerosols. Aside from aerosols transported over long distances, a large part of aerosols is originated at the ground/ocean surface. Anthropogenic activities also release particulates and chemical substances into the atmosphere. Anthropogenic aerosols are also observed on the Pacific Oceans far from the Japan main island (Misaki et al. 1975). Number density of aerosol decreases with the altitude and distance from the sources; its diffusion rate depends on meteorological conditions. Therefore, geographical distribution of aerosol density shows a complex pattern (see a review paper on regional studies in Japan by Morita (1983)), even at a local scale (Endow and Magono 1971). Incessant GSR observation at densely distributed stations has a great advantage for monitoring aerosols.

Furthermore, our method is suitable for monitoring aerosols because we can estimate the Angström's turbidity coefficient instead of the Feussner-Dubois' (or Linke's) factor. As described in Section 3.4, the Angström's turbidity coefficient gives extinction due to aerosols while the FeussnerDubois' (or Linke's) gives extinction due to both aerosols and water vapor. As a result, at stations in isolated islands, the Angström's turbidity remains flat (Fig. 1); however, the Feussner-Dubois' (or Linke's) turbidity shows seasonal variation, especially at southern stations where the warm atmosphere can contain much water vapor. The JMA publishes the Feussner-Dubois' turbidity from DSR observation. Effective transmissivity proposed by Murai and Yamauchi (1975) is also contributed from both aerosols and water vapor. However, $\beta^{\prime}$ gives atmospheric turbidity contributed from only aerosols.

Nowadays, atmospheric turbidity is monitored using other observation techniques (see also the review paper by Aoki (2008)). Since measurement of atmospheric attenuation at several wavelengths or forward scattering patterns of sunlight gives us more information on size distribution of aerosols, radiation observation using sunphotometers (Shaw 1983) or aureolemeters (Aoki and Fujiyoshi 2003) is carried on worldwide. In recent years, back scattering observation of lidar beam and imaging from artificial satellites are also utilized for monitoring aerosols. Atmospheric turbidity estimated using 
our method will be compared with that estimated using up-to-date observation techniques in future works.

\section{Conclusions}

(1) Atmospheric turbidity has been estimated from the hourly observation data of the GSR under cloudless skies. We find that the best-fit monthly turbidity has a high correlation coefficient (0.60.95 ) with that observed by the JMA. The time series in the estimated atmospheric turbidity can be used to detect the signals that correspond to the sudden increase in the amount of aerosols released by forest fires and Asian dust events.

(2) We can estimate the annual mean and seasonal variations of turbidity at 67 stations all over Japan, and reveal that larger turbidity is observed at stations in urban areas. This method is useful for monitoring aerosol contents in the atmosphere, to detect not only seasonal variations but also temporary phenomena, with a high geographical resolution. That is, the denser geographical distribution of the GSR observation network can potentially compensate for the sparseness of the current DSR observation in Japan.

(3) We can carry out reanalysis of the atmospheric turbidity from the hourly GSR data back to around 1991. Taking seasonal turbidity variation into consideration, we can obtain better GSR estimation and utilize the data in related study fields.

Our method provides monthly turbidity data at a practical level of accuracy; however, noises might also be included. In the future, there is room for improvement of turbidity data with the use of finertuned data sets or adopting better analysis criteria.

\section{Acknowledgments}

We thank Prof. Emeritus J. Kondo for his fruitful comments on this study. We acknowledge two anonymous reviewers for improving the manuscript. For this analysis, we use the meteorological data ("Annual Report of the Japan Meteorological Agency", available in CD-ROMs and in publications) compiled by the JMA. This study was financially supported by the research project of the Ministry of the Environment "Integrated Research on Climate Change Scenarios to Increase Public Awareness and Contribute to the Policy Process (S5)',

\section{References}

Ångström, A., 1961: Techniques of determining the turbidity of the atmosphere. Tellus, 13, 214-223.
Aoki, K., 2008: Aerosols detected from atmospheric radiation observation, Effects of aerosols on climate and atmospheric environment (T. Nakajima and T. Hayasaka eds.), Kisyo Kenkyu Note, No. 218, 81-93 (in Japanese).

Aoki, K., and Y. Fujiyoshi, 2003: Sky radiometer measurements of aerosol optical properties over Sapporo, Japan. J. Meteor. Soc. Japan, 81, 493 513.

Damoah, R., N. Spichtinger, C. Forster, P. James, I. Mattis, U. Wandinger, S. Beirle, T. Wagner, and A. Stohl, 2004: Around the world in 17 dayshemispheric-scale transport of forest fire smoke from Russia in May 2003. Atmos. Chem. Phys., 4, 1311-1321.

Dogniaux, R., 1974: Representation analytique des composantes du rayonnement solaire, Institut Royal de Métèorologie de Belgique, Série A No. 83.

Dogniaux, R., 1994: Prediction of solar radiation in areas with a specific microclimate, Kluwer Academic Publishers, Dordrecht, the Netherlands, 107 pp.

Endow, T., and C. Magono, 1971: Distributions of aerosols in Sapporo in the winter season. J. Meteor. Soc. Japan, 49, 48-55.

Flowers, E. C., R. A. McCormick, and K. R. Kurfis, 1969: Atmospheric turbidity over the United States, 1961-1966. J. Appl. Meteor., 8, 955-962.

Japan Meteorological Agency, 2004: Chapter Topic 1 (pp. 56-60), Climate Change Monitoring Report 2003, Japan Meteorological Agency, Tokyo, Japan, 65 pp. (in Japanese).

Japan Meteorological Agency, 2007: Climate Change Monitoring Report 2006, Japan Meteorological Agency, Tokyo, Japan, 87 pp.

Kaneyasu, N., Y. Igarashi, Y. Sawa, H. Takahashi, H. Takada, H. Kumata, and R. Höller, 2007: Chemical and optical properties of 2003 Siberian forest fire smoke observed at the summit of Mt. Fuji, Japan. J. Geophys. Res., 112, D13214, doi:10.1029/ 2007JD008544.

Kondo, J., 1967: Analysis of solar radiation and downward long-wave radiation data in Japan, The Science Report of the Tôhoku University, Fifth Series Geophysics, 18, 91-124, Sendai, Japan.

Kondo, J., 1994: Solar and atmospheric radiations (pp 55-92), Meteorology of Hydrological Environment (Kondo, J., ed.), Asakura Shoten, Tokyo, Japan, 368 pp. (in Japanese).

Kondo, J., and A. Miura, 1983: Empirical formula of the solar radiation at the ground level and a simple method to examine an inaccurate pyranometer. Tenki, 30, 469-475 (in Japanese).

Lamb, H. H., 1972: Climate: Present, Past and Future, Volume 1 Fundamentals and Climate Now, Methuen \& Co. Ltd., London, 613 pp.

López, G., and F. J. Batlles, 2004: Estimate of the atmospheric turbidity from three broad-band solar radi- 
ation algorithms. A comparative study. Ann. Geophys., 22, 2657-2668.

Mattis, I., A. Ansmann, U. Wandinger, and D. Müller, 2003: Unexpectedly high aerosol load in the free troposphere over central Europe in spring/summer 2003. Geophys. Res. Lett., 30, 2178(ASC-9), doi:10.1029/2003GL018442.

Misaki, M., M. Ikegami, and I. Kanazawa, 1975: Deformation of the size distribution of aerosol particles dispersing from land to ocean. J. Meteor. Soc. Japan, 53, 111-120.

Morita, Y., 1983: Spatial distribution of tropospheric aerosols, Special Issue on Aerosols - Application-, Kisyo Kenkyu Note, No. 146, 51-80 (in Japanese).

Murai, K., and T. Yamauchi, 1975: Distribution of global solar radiation in Japan and effective atmospheric transmissivity. Tenki, 22, 557-562 (in Japanese).

Murayama, T., D. Müller, K. Wada, A. Shimizu, M. Sekiguchi, and T. Tsukamoto, 2004: Characterization of Asian dust and Siberian smoke with multi-wavelength Raman lidar over Tokyo, Japan in spring 2003. Geophys. Res. Lett., 31, L23103, doi:10.1029/2004GL021105.

Nagasawa, K., 1999: Computations of the sunrise and sunset, Chijinshokan, Tokyo, Japan, 160 pp. (in Japanese).
Robinson, N. (ed.), 1966: Solar Radiation, Elsevier, Amsterdam, $347 \mathrm{pp}$

Roosen, R. G., R. J. Angione, and C. H. Klemcke, 1973: Worldwide variations in atmospheric transmission: 1. Baseline results from Smithsonian observations, Bull. Amer. Meteor. Soc., 54, 307-316.

Shaw, G. E., 1983: Sun Photometry, Bull. Amer. Meteor. Soc., 64, 4-10.

Yamamoto, G., M. Tanaka, and K. Arao, 1968: Hemispherical distribution of turbidity coefficient as estimated from direct solar radiation measurements. $J$. Meteor. Soc. Japan, 46, 287-300.

Yamauchi, T., 1995: Statistical analysis of atmospheric turbidity over Japan: The influence of three volcanic eruptions. J. Meteor. Soc. Japan, 73, 91-103.

Yang, Y. Q., Q. Hou, C. H. Zhou, H. L. Liu, Y. Q. Wang, and T. Niu, 2008: Sand/dust storm processes in Northeast Asia and associated large-scale circulations. Atmos. Chem. Phys., 8, 25-33.

Yoshida, S., and S. Shinoki, 1978: Preparation of the maps of monthly mean global solar radiation and its year to year variability for the Japanese Islands, Tenki, 25, 375-389 (in Japanese).

Zha, Y., and L. Li, 2007: Influence of the 17 April 2006 Asian dust storm on Moderate Resolution Imaging Spectroradiometer data for land cover identification. J. Geophys. Res., 112, D14205, doi:10.1029/ 2006JD007869. 